\title{
Damage and permeability around faults: Implications for mineralization
}

\author{
Heather A. Sheldon \\ Commonwealth Scientific and Industrial Research Organisation (CSIRO) Exploration and Mining, \\ P.O. Box 1130, Bentley, WA 6102, Australia \\ Steven Micklethwaite \\ Research School of Earth Sciences, Australian National University, Canberra, ACT 0200, Australia
}

\begin{abstract}
Mineral deposits are commonly hosted by small-displacement structures around jogs in major faults, but they are rarely hosted by the major fault itself. This relationship may be explained by time-dependent fracturing and healing in and around major faults and associated permeability evolution. A damage mechanics formulation is used here to explore the spatial-temporal evolution of damage in and around a fault following a fault-slip event. We show that regions of increased damage rate correspond to the location of mineral deposits and that these areas correspond to areas of aftershocks predicted by stress-transfer modeling. The fault itself enters a healing regime following the slip event; hence, it is expected to become less permeable than the fracture network outside the fault. Our results support the hypothesis that mineralization occurs in a fracture network associated with aftershocks; this may be due to the higher time-integrated permeability of the fracture network relative to the main fault.
\end{abstract}

Keywords: fault, aftershocks, fluid, mineralization, permeability, damage.

\section{INTRODUCTION}

Fault-related hydrothermal deposits are commonly hosted by small-displacement structures clustered around jogs or bends in major faults, while the major structure itself remains poorly endowed (e.g., Cox et al., 2001). Recent work has shown that the location of gold deposits associated with jogs in ancient, crustal-scale, strike-slip faults can be predicted using stresstransfer modeling (Micklethwaite and Cox, 2004, 2006; Cox and Ruming, 2004), a technique that is more widely known as a tool for predicting the location of aftershocks (e.g., King et al., 1994; Freed, 2005). The spatial distribution of aftershocks or mineralization is predicted by identifying areas that have been brought closer to failure as a consequence of the instantaneous stress change due to a specified faultslip event. While this technique is useful for predicting the location of mineral deposits, it does not explain why small-displacement structures are more favorable for mineralization than the major structure with which they are associated. One hypothesis is that the aftershock fracture network remains permeable over a longer period of time than the main fault, and, hence, it can accommodate a larger time-integrated fluid flux (Micklethwaite and Cox, 2004, 2006). The characteristic temporal decay of aftershocks (Utsu et al., 1995; Omori, 1894) suggests that aftershock fracture networks could remain permeable for days or months, while the main fault is rapidly sealed following a slip event. However, such time-dependent behavior cannot be represented by stress-transfer modeling. We address this limitation by using damage mechanics to simulate time-dependent fracturing and healing in and around a fault, and we show for the first time how this approach can be used to explore the time dependence of permeability and fluid flow in mineralizing fault systems.

\section{THEORETICAL BACKGROUND}

Stress-transfer modeling predicts the spatial distribution of aftershocks by calculating the instantaneous stress change caused by a faultslip event, assuming poroelastic behavior, and using this to identify areas where faults of a given orientation have been brought closer to failure (King et al., 1994). This is achieved by calculating the change in Coulomb failure stress $\left(\Delta \sigma_{f}\right)$, which is defined as:

$$
\Delta \sigma_{\mathrm{f}}=\Delta \tau+\mu^{\prime} \Delta \sigma_{\mathrm{n}}
$$

where $\tau$ and $\sigma_{\mathrm{n}}$ are the shear stress and normal stress acting on a plane of specified orientation (tensile stress positive), and $\mu^{\prime}$ is the apparent coefficient of friction, which accounts for the effect of fluid pressure on normal stress in a poroelastic medium. Positive values of $\Delta \sigma_{\mathrm{f}}$ indicate that the stress state has moved closer to failure.

The value of stress-transfer modeling for predicting the location of aftershocks and estimating seismic hazard is well established (e.g., Freed, 2005), and a number of studies have used similar techniques to explore other aspects of stress changes associated with faulting, such as rotation of secondary faults (Maerten et al., 2002), the development of fault shapes (Martel, 1999), and interaction between fault segments (Crider and Pollard, 1998). However, the methods employed in these studies do not represent any time-dependent processes that could explain the temporal characteristics of active fault zones, such as the temporal decay of aftershocks. This time dependence is important for understanding the relationship between aftershocks and mineralization that has been inferred from stress-transfer modeling (Micklethwaite and Cox, 2004, 2006). Lyakhovsky et al. (2005) compared two approaches for modeling time-dependent mechanical behavior in the brittle crust, namely, damage mechanics and rateand state-dependent friction (rate-state friction; Dieterich, 1994). Damage mechanics is a continuum approach that represents the evolution of mechanical properties associated with the formation and healing of fractures in a volume of rock, whereas rate-state friction describes the evolution of frictional properties on predefined planes of weakness. We have chosen to use damage mechanics in preference to rate-state friction for our investigation of time-dependent fracturing around a fault, because this approach removes the need to define the location and orientation of structures in the wall rocks.

Damage mechanics represents behavior associated with time- and stress-dependent fracturing (damage) during rock deformation. The theory of damage mechanics follows the principles of irreversible thermodynamics to account for the evolution of surface energy associated with formation and healing of cracks (Lyakhovsky et al., 1997). Rock deformation experiments indicate that macroscopic failure is preceded by distributed microcracking associated with a reduction 
in the elastic moduli (e.g., Lockner, 1995; Scholz, 1990). Macroscopic failure occurs when microcracks interact to form a through-going fracture, and propagating fractures are preceded by a process zone of distributed cracking. Analogous behavior is believed to occur on the decimeter to kilometer scale, where distributed fracturing is a precursor to the development of faults or shear zones, and slip on existing faults results in fracturing of the surrounding rock. These phases of distributed fracturing before and after a faultslip event may be associated with foreshocks and aftershocks, respectively (Main, 2000). Damage mechanics encapsulates these aspects of rock behavior using a smooth continuum approach, whereby fracturing is represented by a scalar damage parameter that represents the density of fractures in a representative volume of rock. The relationship between damage mechanics and other methods for modeling fracture propagation, such as linear elastic fracture mechanics and "cohesive end zone" models, is discussed by Lyakhovsky et al. (1997). The damage mechanics method is more flexible than these methods because it permits modeling of rock deformation in systems of arbitrary geometry, and it can represent both the formation and propagation of macroscopic fractures.

In this paper, we use the damage mechanics formulation of Hamiel et al. (2004) and Lyakhovsky et al. (1997) to explore damage evolution associated with the three-dimensional (3-D) elastic strain field around a fault. This formulation has been validated by comparison with experimental results (Hamiel et al., 2004, 2006; Lyakhovsky et al., 2005). The damage rate is expressed as:

$$
\frac{d \alpha}{d t}=C I_{2}\left(\alpha^{\beta} \xi-\xi_{0}\right),
$$

where $0<\alpha<1$ is damage; $\xi_{0}$ and $\beta$ are constants; $\mathrm{C}$ is a kinetic parameter; and $\xi=I_{1} / \sqrt{I_{2}}$ is a function of two invariants of the elastic strain tensor $\left(I_{1}=\varepsilon_{i i}\right.$ and $I_{2}=\varepsilon_{i j} \varepsilon_{i j}$, where dilation is positive and Einstein summation applies). A positive damage rate represents formation of fractures, while a negative damage rate represents healing. Stress and elastic strain are related by a modified form of Hooke's law in which the Lamé parameters are functions of strain and damage. The formulation has a "viscous" component, which reflects gradual conversion of elastic strain to irreversible strain $\left(\varepsilon_{i j}^{v}\right)$. Further details of the governing equations can be found in the GSA Data Repository. ${ }^{1}$

${ }^{1}$ GSA Data Repository item 2007223, further details of the equations for damage and permeability evolution, is available online at www.geosociety. org/pubs/ft2007.htm, or on request from editing@ geosociety.org or Documents Secretary, GSA, P.O. Box 9140, Boulder, CO 80301, USA.
Equation 2 defines three damage rate regimes that have been described as healing, stable weakening, and unstable weakening (Hamiel et al., 2004). These regimes are illustrated in Figure 1. The transition from healing (negative damage rate) to stable weakening (positive damage rate) occurs at $\alpha^{\beta} \xi=\xi_{0}$, and the transition to unstable weakening occurs at $\xi=\xi_{0}$. Healing is favored by compaction and low shear strain, whereas dilation and high shear strain favor weakening. We make a distinction between healing and sealing; healing may involve local redistribution of chemical components, but this should not be confused with sealing of fractures by minerals precipitated from a fluid moving through the fracture.

Arrows in Figure 1 illustrate the effect of an instantaneous change in $\xi$ from a point on the zero damage rate curve, followed by evolution of damage at constant $\xi$. This change in $\xi$ could be the change in elastic strain associated with a fault-slip event, for example. Path A takes the rock into the healing regime, where the damage rate is negative and tends to zero with decreasing damage. Path B takes the rock into the stable weakening regime, where the damage rate is positive and tends to zero with increasing damage. Path $\mathrm{C}$ moves the rock into the unstable weakening regime, where damage increases to the maximum possible value ( $\alpha \leq 1$; see Lyakhovsky et al. [1997] for discussion of maximum damage), at which point macroscopic failure occurs, and the deviatoric stress is assumed to drop to zero. This means that $\xi$ is reduced to its minimum value $(-\sqrt{3})$, and, hence, the rock enters the healing regime following macroscopic failure. Macroscopic failure can be interpreted as an earthquake triggered

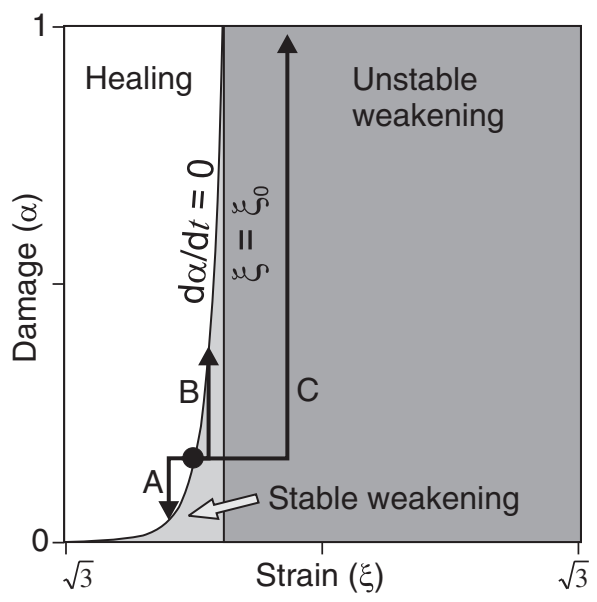

Figure 1. Damage regimes defined by Equation $2\left(\xi_{0}=-0.62, \beta=0.15\right)$. Stable weakening regime is delimited by curves $\mathrm{d} \alpha / \mathrm{d} t=0$ and $\xi=\xi_{0}$. Paths A, B, and C demonstrate effect of a change in $\xi$ followed by evolution of $\alpha$ at constant $\xi$ in healing, stable weakening, and unstable weakening regimes. by the initial slip (strain) event, while damage represents smaller seismic events responsible for aftershocks. The decay of damage rate with time in the stable weakening regime is analogous to the characteristic temporal decay of aftershocks (Ben-Zion and Lyakhovsky, 2006; Shcherbakov and Turcotte, 2004). In the following analysis, we treat a slip event on a major fault as a macroscopic failure event and explore the consequences of that event for damage evolution in and around the fault.

\section{DAMAGE EVOLUTION IN AND AROUND FAULTS}

Here, we illustrate application of the damage mechanics formulation to an idealized strike-slip fault, and then we apply the approach to a real example of a mineralized strike-slip fault system.

The idealized fault is a vertical rectangular plane that is $10 \mathrm{~km}$ long and extends vertically from 5 to $15 \mathrm{~km}$ depth. The size of the modeled area is $40 \times 40 \times 20 \mathrm{~km}$ centered around the fault. The stress state prior to fault slip is as follows: $\sigma_{2}$ vertical, determined by the weight of overburden at a density of $2900 \mathrm{~kg} / \mathrm{m}^{3} ; \sigma_{1}$ and $\sigma_{3}$ oriented horizontally at $030^{\circ}$ and $120^{\circ}$. The initial value of $\alpha$ is determined from Equation 2 , assuming $d \alpha / d t=0$, and using the value of $\xi$ corresponding to the initial stress state. The instantaneous change in stress and elastic strain arising from $0.5 \mathrm{~m}$ of dextral slip is calculated using COULOMB v. 2.6, a boundaryelement code designed for stress-transfer modeling (Toda et al., 1998). This code assumes that the rock mass behaves as a linear elastic material, which is a reasonable approximation for the purpose of our calculations. Damage rate is calculated from the elastic strain using Equation 2. To explore the temporal evolution of damage following the slip event, we use a numerical method to solve the coupled, nonlinear equations for elastic strain, stress, and damage, assuming that the total strain (elastic plus inelastic) remains constant with time after the slip event. The fault was treated as a plane in COULOMB v. 2.6, but we treat it as a region of finite width for the purpose of exploring damage evolution within the fault. This is achieved by assigning maximum damage $(\alpha=1)$ and lithostatic stress to points in the model that lie immediately on either side of the fault. Parameter values used in the simulations are listed in the GSA Data Repository (see footnote 1).

Figure 2A shows the damage rate on a horizontal plane at $10 \mathrm{~km}$ depth immediately after the slip event. The stress change due to fault slip caused the $\xi-\alpha$ state to move away from the zero damage rate curve into the healing and stable weakening regimes (paths A and B in Fig. 1). Lobes of high positive damage rate occur at each end of the fault, corresponding 

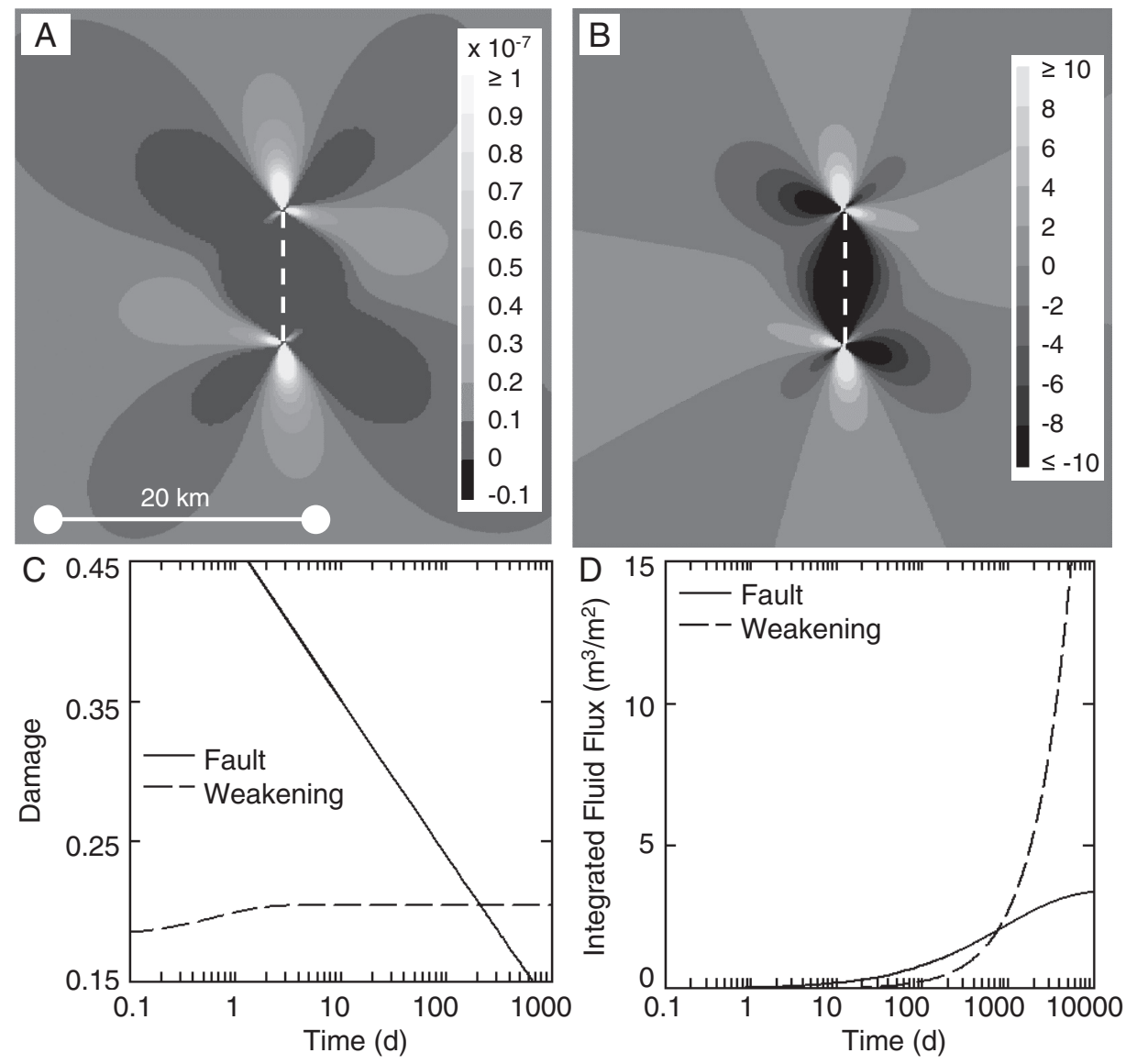

Figure 2. Damage rate $\left(\mathrm{s}^{-1}\right)(\mathrm{A})$ and $\Delta \sigma_{\mathrm{f}}$ (bars) (B) immediately after a dextral-slip event on an idealized vertical strike-slip fault. Fault is shown as dashed white line. Results are shown on a horizontal plane at $10 \mathrm{~km}$ depth. C: Evolution of damage in fault and in area of weakening outside of fault. D: Evolution of time-integrated fluid flux at same points as in C, assuming a power-law relationship between damage and permeability (see text footnote 1).

to areas of increased shear strain (extending beyond the ends of the fault) and dilation (lateral lobes either side of the fault). The wall rocks along the length of the fault have entered the healing regime due to the reduction in shear strain associated with fault slip. The fault itself has the lowest (most negative) damage rate, but this cannot be identified from Figure 2A because the positive values are orders of magnitude larger due to the difference in the kinetic parameter $C$ for healing and weakening (see footnote 1). For comparison, Figure 2B shows the distribution of $\Delta \sigma_{f}$. The patterns of damage rate and $\Delta \sigma_{\mathrm{f}}$ are very similar, where lobes of positive damage rate correspond very closely to lobes of positive $\Delta \sigma_{\mathrm{f}}$. The similarity arises because the factors that control the change in damage rate (change in volumetric strain and shear strain) are closely related to the factors that control $\Delta \sigma_{\mathrm{f}}$ (change in normal stress and shear stress), although there is a subtle difference because $\Delta \sigma_{\mathrm{f}}$ is insensitive to the intermediate principal stress.

Figure $2 \mathrm{C}$ shows the evolution of damage at a point within the fault and at a point in an area of stable weakening outside the fault. Note the log scale on the time axis. Damage in the fault starts from a high value ( $\alpha=1$ at $t=0)$ but is rapidly reduced by healing, until it drops below the original value in the wall rocks after $\sim 200 \mathrm{~d}$. Outside the fault, in areas of stable weakening, damage increases to reach a new steady-state value within a few days as the damage rate decays to zero.

The initial condition of our model on the zero damage rate curve and the relatively small strain associated with a single slip event dictate that the $\xi$ - $\alpha$ state lies entirely within the stable weakening and healing regimes immediately after the slip event, and the resulting increase in damage in areas of stable weakening is quite small (Fig. 2C). Repeated slip events, increasing $\xi$ with time (e.g., due to regional deformation), or starting the model at higher $\xi$ could push some areas into the unstable weakening regime, where damage can increase to much higher values, leading to formation of new faults and/or reactivation of existing structures in the aftershock region.

Figure 3 demonstrates application of the damage mechanics formulation to the Black

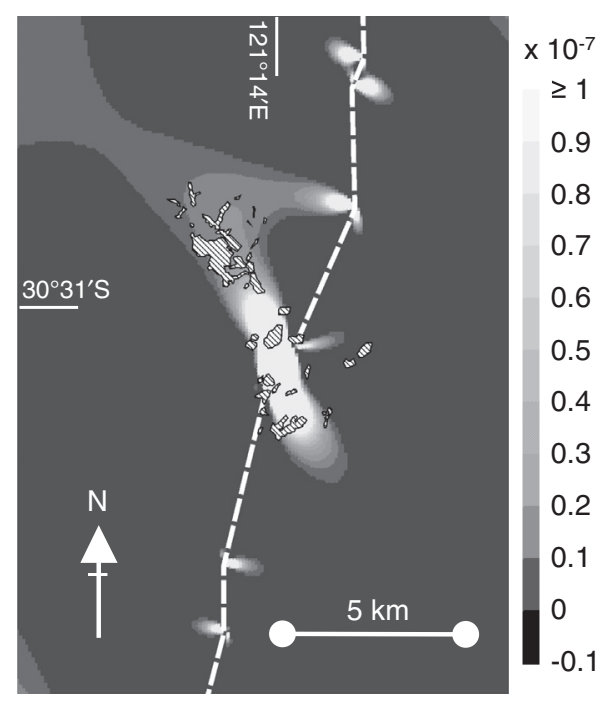

Figure 3. Damage rate $\left(\mathrm{s}^{-1}\right)$ immediately after dextral-slip events terminating at jog in Black Flag fault, Western Australia. Fault is shown as dashed line. Shaded areas indicate known gold mineralization.

Flag fault, a crustal-scale, strike-slip fault system in Western Australia. Micklethwaite and Cox $(2004,2006)$ showed that the distribution of gold deposits around a jog in this fault corresponds closely to the region of positive $\Delta \sigma_{f}$ due to dextral-slip events terminating at the jog. We used their stress-transfer modeling results to calculate the damage rate, revealing a strong positive correlation between areas of increased damage rate and the location of mineralization (Fig. 3).

\section{DISCUSSION}

The damage mechanics approach described here provides a framework for future work in exploring the evolution of permeability and fluid flow following a fault-slip event. Assuming that damage is positively correlated with permeability, we predict that the fault would be a high-permeability pathway immediately following the slip event, but its permeability would be rapidly reduced by healing (cf. Fig. 2C). Conversely, areas of positive damage rate around the fault would undergo an increase of permeability. These areas could therefore accommodate a larger time-integrated fluid flux than the main fault, which would explain the enhanced mineralization potential of the aftershock fracture network. This is illustrated in Figure 2D, which shows evolution of the time-integrated fluid flux at a point in the fault and in an area of positive damage rate outside the fault, assuming a lithostatic fluid pressure gradient and a simple power-law relationship between damage and permeability (see footnote 1 ).

In this study, we used a mechanical formulation to represent time-dependent behavior 
responsible for aftershocks and mineralization. Other authors have attributed the timedependence of aftershocks to migration of overpressured pore fluids (e.g., Miller et al., 2004; Antonioli et al., 2005; Nur and Booker, 1972). In reality, the effects of damage and fluid pressure must be strongly coupled, since damage influences permeability and, hence, flow, while changes in pore fluid pressure associated with movement of overpressured fluids will impact on mechanical behavior. These interactions, along with the effect of chemical sealing on permeability, can be explored using 3-D numerical models that consider the coupled evolution of elastic and inelastic strain, damage, permeability, and fluid pressure both before and after a slip event.

Previous work has shown that the location of gold deposits around some ancient strike-slip fault systems corresponds to the location of aftershocks predicted by stress-transfer modeling (Micklethwaite and Cox, 2004, 2006; Cox and Ruming, 2004). It has been suggested that the enhanced mineralization potential of the aftershock fracture network relative to the main fault could be explained by a higher time-integrated permeability in the fracture network, and this theory is supported by the characteristic temporal decay of aftershocks. Stress-transfer modeling cannot explain or predict this time-dependent aspect of aftershocks and permeability evolution. Using a damage mechanics formulation, we have shown that areas of positive damage rate correspond closely to the location of known mineralization and to areas of aftershocks determined by stress-transfer modeling, and that the main fault enters a healing regime following the slip event. Our results are consistent with the hypothesis that the enhanced mineralization potential of the aftershock fracture network is due to its higher time-integrated permeability relative to the main fault, assuming a positive correlation between damage and permeability.

In this paper, we have emphasized the significance of damage and associated permeability evolution for the formation of hydrothermal ore deposits, but our findings have relevance to any system involving fluid flow through fractured rocks, e.g., hydrocarbon migration or geothermal systems. The approach described in this paper represents a step forward in understanding the factors controlling permeability in fractured low-porosity rocks, an area that is poorly understood in comparison with the extensive body of knowledge concerning permeability of faults in sedimentary basins (e.g., Jones et al., 1998). In addition, the combination of damage mechanics with stress-transfer modeling provides an alternative to rate-state friction theory for exploring time-dependency of aftershocks and migration of seismicity away from rupture sites.

\section{CONCLUSION}

We have shown that the distribution of damage around a fault has a strong positive correlation with the distribution of mineralization and with the distribution of aftershocks predicted by stress-transfer modeling of mineralized fault systems. The damage mechanics formulation suggests a physical explanation for timedependent fracturing in the brittle crust and provides a framework for exploring the evolution of permeability and fluid flow through mineralized fault systems.

\section{ACKNOWLEDGMENTS}

This work is published with permission of sponsors of the Australian Mineral Industries Research Association International project P718A and the Chief Executive Officer of the Predictive Mineral Discovery Cooperative Research Centre. We thank the U.S. Geological Survey for making COULOMB 2.6 freely available.

\section{REFERENCES CITED}

Antonioli, A., Piccinini, D., Chiaraluce, L., and Cocco, M., 2005, Fluid flow and seismicity pattern: Evidence from the 1997 Umbria-Marche (central Italy) seismic sequence: Geophysical Research Letters, v. 32, p. L10311, doi: 10.1029/2004GL022256.

Ben-Zion, Y., and Lyakhovsky, V., 2006, Analysis of aftershocks in a lithospheric model with seismogenic zone governed by damage rheology: Geophysical Journal International, v. 165 , p. 197-210, doi: 10.1111/j.1365-246X. 2006.02878.x.

Cox, S.F., and Ruming, K., 2004, The St. Ives mesothermal gold system, Western AustraliaA case of golden aftershocks?: Journal of Structural Geology, v. 26, p. 1109-1125, doi: 10.1016/j.jsg.2003.11.025

Cox, S.F., Knackstedt, M.A., and Braun, J., 2001, Principles of structural control on permeability and fluid flow in hydrothermal systems: Reviews in Economic Geology, v. 14, p. 1-24.

Crider, J.G., and Pollard, D.D., 1998, Fault linkage: Three-dimensional mechanical interaction between echelon normal faults: Journal of Geophysical Research, v. 103, p. 24,373-24,391.

Dieterich, J., 1994, A constitutive law for rate of earthquake production and its application to earthquake clustering: Journal of Geophysical Research, v. 99 , p. 2601-2618, doi: 10.1029/93JB02581.

Freed, A.M., 2005, Earthquake triggering by static, dynamic, and postseismic stress transfer: Annual Review of Earth and Planetary Sciences, v. 33, p. 335-367, doi: 10.1146/annurev. earth.33.092203.122505.

Hamiel, Y., Liu, Y., Lyakhovsky, V., Ben-Zion, Y., and Lockner, D., 2004, A visco-elastic damage model with applications to stable and unstable fracturing: Geophysical Journal International, v. 159 , p. $1155-1165$, doi: $10.1111 / j .1365-$ 246X.2004.02452.x.

Hamiel, Y., Katz, O., Lyakhovsky, V., Reches, Z., and Fialko, Y., 2006, Stable and unstable damage evolution in rocks with implications to fracturing of granite: Geophysical Journal International, v. 167 , p. 1005-1016, doi: 10.1111/ j.1365-246X.2006.03126.x.

Jones, G., Fisher, Q.J., and Knipe, R.J., eds., 1998, Faulting, Fault Sealing and Fluid Flow in Hydrocarbon Reservoirs: Geological Society of London Special Publication 147, 319 p.
King, G.C.P., Stein, R.S., and Lin, J., 1994, Static stress changes and the triggering of earthquakes: Bulletin of the Seismological Society of America, v. 84, p. 935-953.

Lockner, D.A., 1995, Rock failure, in Ahrens, T.J., ed., Rock Physics and Phase Relations: A Handbook of Physical Constants: Washington, D.C., American Geophysical Union, p. $127-147$.

Lyakhovsky, V., Ben-Zion, Y., and Agnon, A., 1997, Distributed damage, faulting, and friction: Journal of Geophysical Research, v. 102 , p. 27,635-27,649, doi: 10.1029/97JB01896.

Lyakhovsky, V., Ben-Zion, Y., and Agnon, A., 2005, A visco-elastic damage rheology and rate- andstate-dependent friction: Geophysical Journal International, v. 161, p. 179-190, doi: 10.1111/ j.1365-246X.2005.02583.x.

Maerten, L., Gillespie, P., and Pollard, D.D., 2002, Effects of local stress perturbation on secondary fault development: Journal of Structural Geology, v. 24, p. 145-153.

Main, I.G., 2000, A damage mechanics model for power-law creep and earthquake aftershock and foreshock sequences: Geophysical Journal International, v. 142, p. 151-161, doi: 10.1046/ j.1365-246x.2000.00136.x.

Martel, S.J., 1999, Mechanical controls on fault geometry: Journal of Structural Geology, v. 21, p. 585-596.

Micklethwaite, S., and Cox, S.F., 2004, Faultsegment rupture, aftershock-zone fluid flow, and mineralization: Geology, v. 32, p. 813 816, doi: 10.1130/G20559.1.

Micklethwaite, S., and Cox, S.F., 2006, Progressive fault triggering and fluid flow in aftershock domains: Examples from mineralized Archaean fault systems: Earth and Planetary Science Letters, v. 250 , p. $318-330$, doi: 10.1016/j.eps1.2006.07.050.

Miller, S.A., Collettini, C., Chiaraluce, L., Cocco, M., Barchi, M., and Kaus, B.J.P., 2004, Aftershocks driven by a high-pressure $\mathrm{CO}_{2}$ source at depth: Nature, v. 427 , p. $724-727$, doi: 10.1038/nature02251.

Nur, A., and Booker, J.R., 1972, Aftershocks controlled by pore fluid flow?: Science, v. 175 , p. 885-887, doi: 10.1126/science.175.4024.885.

Omori, F., 1894, On the aftershocks of earthquakes: Journal of College Science, Imperial University of Tokyo, v. 7, p. 111-120.

Scholz, C.H., 1990, The Mechanics of Earthquakes and Faulting: Cambridge, Cambridge University Press, $439 \mathrm{p}$.

Shcherbakov, R., and Turcotte, D.L., 2004, A damage mechanics model for aftershocks: Pure and Applied Geophysics, v. 161, p. 2379 2391, doi: 10.1007/s00024-004-2570-x.

Toda, S., Stein, R.S., Reasenberg, P.A., Dieterich, J.H., and Yoshida, A., 1998, Stress transferred by the 1995 M-W $=6.9$ Kobe, Japan, shock: Effect on aftershocks and future earthquake probabilities: Journal of Geophysical Research, v. 103 , p. $24,543-24,565$, doi: 10.1029/98JB00765.

Utsu, T., Ogata, Y., and Matsuura, R.S., 1995, The centenary of the Omori formula for a decay law of aftershock activity: Journal of Physics of the Earth, v. 43, p. 1-33.

Manuscript received 7 March 2007

Revised manuscript received 18 May 2007

Manuscript accepted 22 May 2007

Printed in USA 